\title{
Le-ADS: Early Learning Disability Detection System for Autism and Dyslexia
}

\author{
Nor'ain Mohd Yusoff, Nor Syarafina Rusli, and Ruhaiza Ishak \\ Faculty of Information Technology, Multimedia University Malaysia, \\ 63100 Cyberjaya, Selangor, Malaysia \\ norain.yusoff@mmu. edu.my, \\ \{syara.nor, bobogulz\} @gmail.com
}

\begin{abstract}
Screening test is one of common approaches to detect learning disabilities among children. The Early Learning Disability Detection System for Autism and Dyslexia (Le-AdS) is developed to help primary school teachers to recognize signs and students' behaviour. Studies and researches for the system have been done to understand these types of disorder. Research on the system architecture has also been carried out to know how the system should work based on the requirements and needs of the user. Interviews, reading and overview have been applied throughout the development process of this standalone software. This paper presents the work of Early Learning Disability Detection for Autism and Dyslexia (Le-ADS).
\end{abstract}

Keywords: Mild Autism, Dyslexia, Screening System, Learning Disability.

\section{Introduction}

In Malaysia, autism and dyslexia syndrome still have a cloud of stigma over it with many blaming parents for the misdeed that led the child to being punished [7]. According to Dyslexia Association of Sarawak president Dr. Ong Puay Hoon, there are more than 850000 Form One students in our country who are unable to read and write appropriately because of these syndromes. This is a disturbing scenario because if these children are educated based on appropriate and suitable curriculum they may have chances in becoming successful and intelligent like any normal individuals. In order to educate these types of children, they need to be taught based on the correct learning methods. The Ministry of Education has provided special syllabus to teach dyslexic and autistic pupils. The problem is to categorize them accordingly. The existing method that was introduced by the ministry was basically based on teachers understanding on students' academic performance, not characteristic of any learning disabilities. Furthermore, it does not provide students involvement directly. To divide these children accordingly, a reliable screening tool is needed to support the test done by teachers. The paper describes the problem statements, research methods and related works with regards to autism and dyslexia problem. It features present the system of Le-ADS, its features and implication to the users. 


\section{Problem Statement}

In Malaysia, children with dyslexic and autism are being neglected in a way that they do not get a proper education compared to children without the problem of learning disorder. There are no integrated systems used by the Education Department in order to help teachers to screen and categorized these 'special' students accordingly. This will bring difficulties to inexperience teachers and those with deficient information on the disorders; and due to these it will directly affect students. The problems identified are as follows:

- Inexperience teachers - New teachers graduating in the field are qualified teachers, but most of them have never gained a firsthand experience, except for what they learned in lectures or through briefings.

- Lack of information on the symptoms related - Teachers need to do their own research and study on the symptoms in order to understand students "behaviour and learning problem. Information given by the parents or paediatricians is too general, in which just basically stated the disability type.

- Students are being neglected - Students for both disabilities need different learning methods. If they are carelessly screened, they will be allocated in different classes with another type of learning techniques; the one which they don't essentially need.

- 'They do not look disabled' condition - Since the disabilities did not revealed physical sign, some teachers will simply assume that the children are acting lazy and not focused in class. [1]

\section{Research Methodology}

The methods included in the research are library search and interviews from selected participants. Library search involved extracting information from various reading sources that includes books, journals and research papers. Interviews involved respondents from NASOM (The National Autism Society of Malaysia), Temiang Primary School and Taman Tuanku Jaafar 2 Primary School. These references are accurate, comprehensible, and most importantly dependable in order to gain more information associated with learning disabilities, particularly autism and dyslexia. The interviews are extracted to gain the needed information. The selections are labelled as Sample I, Sample II and Sample III. For Sample I, the interview was conducted with the respondent from NASOM Intervention Program. Respondent is an experience teacher in training and managing children with Autism. Sample II shows the extraction from the interview with respondent from Temiang Primary School. Besides being a coordinator, the respondent is also experienced in teaching dyslexic students and has participated in several courses on the subject of Dyslexia. Sample III consists of extraction from interview with respondent from Taman Tuanku Jaafar 2 Primary School. The respondent has been a teacher for 16 years and is experienced in educating primary school students with learning disabilities. 


\section{Sample I}

Interviewer: What is Autism?

Respondent: A lifelong developmental disorder that prevents a child from having the ability to learn and to be able to master language and communication skills.

Interviewer: What are the characteristic of an autistic child in terms of behaviour?

Respondent: They do not have any eye to eye interactions with the people around them (unusual eye contact), tend to ignore questions or instructions and sometimes prone to be echolalia, unusual attachment to certain object (e.g. toy car), showing emotions inappropriately at unsuitable places and they have no fear of real danger.

Interviewer: What are the characteristics of an autistic child in terms of their physical appearance?

Respondent: An autistic child or adult look like any normal people with no disabilities. [5]

\section{Sample II}

Interviewer: What is Dyslexia?

Respondent: Students that are dyslexic are those that have difficulties in recognizing alphabets, constructing words and phrases. At early stage, they tend to have difficulties identifying left and right; up and down and the concept of in front and behind. They have problems memorizing the words that have been taught to them; and have problem with words that are similar in sounds. Dyslexic people tend to use the right side of the brain more than the left side. These children are considered weak when it comes to language, logics and structures.

Interviewer: What are the characteristics of a dyslexic student in terms of behaviours?

Respondent: Behaves like normal children (normal here means that they can play, talk, understand instructions and can think of actions), unable to focus during class, likely to avoid reading activities.

Interviewer: How about their criteria in terms of physical features?

Respondent: Physically, these kids look exactly like normal kids with no difficulties. [3]

\section{Sample III}

Interviewer: What is Special Recovery Program?

Respondent: The Special Remedial Program ('Program Pemulihan Khas') is an education plan set by the Malaysia Ministry of Education for primary school students that have complex problem of learning the basic skills of 3M. $3 \mathrm{M}$ is an abbreviation for "membaca, menulis, mengira" (read, write, count).

Interviewer: Who are the students that are in the program?

Respondent: The ones that are unable to read, write and count correctly; and those who cannot master the $3 \mathrm{M}$ skills because of surrounding factors not cognitive disabilities.

Interviewer: How old are the students in this program? 
Respondent: The age for student in this program is eight to nine years old. They don't have to be in the program for the whole two year period. Once the students are able to adapt to $3 \mathrm{M}$ skills, they are shifted back to regular classes. [2]

\section{LE-ADS System}

Le-ADS is a software to assist teachers and school principals to divide possible autistic or dyslexic students and the end result from this screening system will be a reference for teachers and school principals to provide appropriate learning curriculums for dyslexic and autistic children. Underlying Spiral Model Development Life Cycle, the software was implemented based on the qualifiers by [1], and findings from [2], [3] and [4]. The objectives of implementing Le-Ads as follows:

- To assist teachers in categorizing dyslexic or autistic students

- To help principals to differentiate dyslexic or autistic children in school

- To associate dyslexic and autistic students with appropriate syllabus.

\subsection{System Screen Shots: Examples on the Autism and Dyslexia Results}

The screen shots below show the examples on how results for autism and dyslexia are obtained. In the STUDENT PROFILE page shown in Fig 1, teacher enters students' particulars and record. Next, in Fig. 2, teacher proceeds the test together with student by asking questions with the choices of Yes and No options. The Result Page in Fig. 3 displays Student's Name, ID, Teacher's Name and Test Result

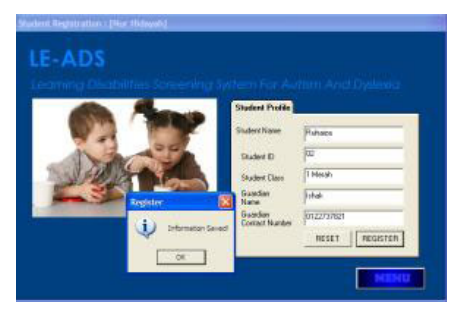

Fig. 1. Student Profile Menu
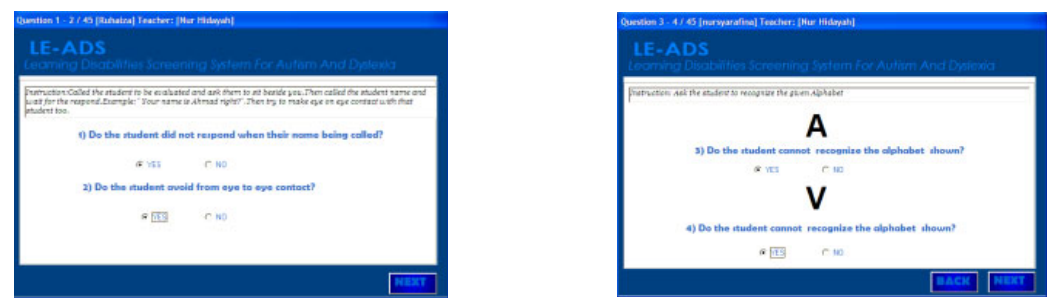

Fig. 2. Examples of Questions 

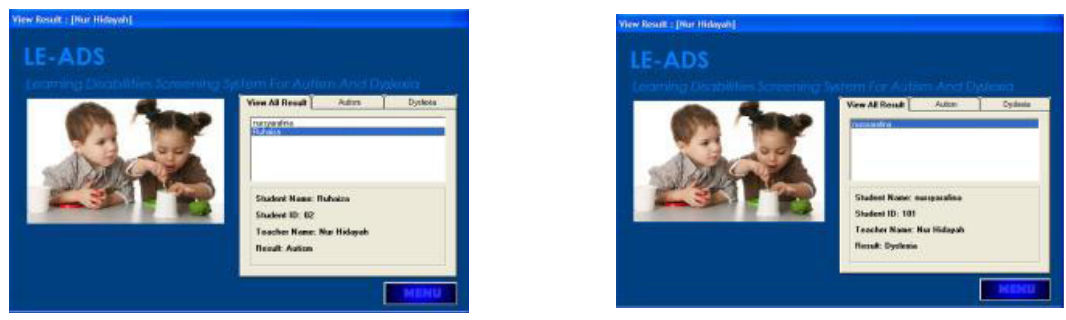

Fig. 3. Examples of Autism or Dyslexia Learning Disability Result

\section{Conclusions}

There are some significance in implementing the Early Learning Disability Detection System for Autism and Dyslexia (Le-ADS). The standalone software enables teachers to construct their own conclusion based on first-hand experience, not just depending on pediatricians' report which sometimes can be too general or technical. The system that acts as an early detection system is able to help teachers in categorizing the students and proceed to deciding which curriculums are suitable for students, based on the type of disorder. Teachers will be able to provide more attention to students, corresponding to the students learning problems. With the existence of the software, the school principals may acknowledge that such disabilities cases exist and in a way exposed parents to the importance of detecting learning disabilities at early stage.

\section{References}

1. Abdul Wahab, M.H., Aziz, M.A., Asha'ari, F.J.: Expert System for Special Education (Final Year Project). Faculty of Information Science and Technology, Multimedia University Malaysia, Melaka (2007)

2. Abdullah, P.N.H.: Special Remedial Program in Sekolah Kebangsaan Taman Tuanku Jaafar 2, Sungai Gadut (March 31, 2010) (An Interview)

3. Darus, M.S.B.H.M.: Dyslexia Program in Sekolah Kebangsaan Temiang. Negeri Sembilan (April 2, 2010) (An Interview)

4. LUCID COPS, http: / /www. lucid.research. com (retrieved November 8, 2009)

5. Mintol, P.Y.: The National Autism Society of Malaysia (NASOM), Intervention Program. Seremban, Negeri Sembilan (March 29, 2010) (An Interview)

6. Mohd Yusoff, N., Abdul Wahab, M., Aziz, M., Jalil Asha'ari, F.: ESSE: Learning disability classification system for autism and dyslexia. In: Stephanidis, C. (ed.) UAHCI 2009. LNCS, vol. 5614, pp. 395-402. Springer, Heidelberg (2009)

7. Najar, E.: The Multi-Faceted Expression of Autism. New Straits Time Online (News Image Bank), p. 009 (July 1, 2010), http: / / www.nib.com.my (retrieved) 